\section{Case Reports in Neurology}

Case Rep Neurol 2021;13:31-34

DOI: 10.1159/000511311

Published online: January 21, 2021
(C) 2021 The Author(s)

Published by S. Karger AG, Basel OPEN

www.karger.com/crn

This article is licensed under the Creative Commons Attribution-NonCommercial 4.0 International License (CC BY-NC) (http://www.karger.com/Services/OpenAccessLicense).

Usage and distribution for commercial purposes requires written permission.

\title{
Inner-Ear Symptom May Herald Basilar Artery Occlusion
}

\author{
Yosuke Aiba $^{a} \quad$ Ryuji Sakakibara $^{a} \quad$ Takashi Yamaguchi $^{b} \quad$ Fuyuki Tateno $^{a}$ \\ ${ }^{a}$ Neurology, Internal Medicine, Sakura Medical Center, Toho University, Sakura, Japan; \\ ${ }^{b}$ Diabetes and Metabolism, Internal Medicine, Sakura Medical Center, Toho University, \\ Sakura, Japan
}

\section{Keywords}

Inner ear · Labyrinthine artery · Anterior inferior cerebellar artery · Basilar artery

\begin{abstract}
A 75-year-old Japanese man suddenly experienced right cochlear and vestibular dysfunction. Basilar artery occlusion and silent right cerebellar infarction were identified 3 days later. These were treated with intravenous ozagrel (an antiplatelet agent) and edaravone, a free-radical scavenger. The patient did not develop cerebello-brainstem signs. His first sign most probably reflected a right labyrinthine artery occlusion that heralded, or occurred together with, the basilar artery occlusion. This case highlights the possibility that a sudden inner ear dysfunction may herald a basilar stroke. Clinicians should therefore initiate appropriate therapy to prevent life-threatening brainstem complications.

(C) 2021 The Author(s)

Published by S. Karger AG, Basel
\end{abstract}

\section{Introduction}

Retinal artery occlusion (sudden visual loss in one eye) may herald a hemispheric stroke [1], since the central retinal/ophthalmic artery bifurcates from the internal carotid artery. Similarly, labyrinthine artery occlusion (sudden deafness and vertigo in one ear) may herald a basilar stroke [2], since the labyrinthine artery bifurcates from the anterior inferior cerebellar artery (AICA) originating from the basilar artery [3]. Here, we provide the case of an elderly 


\section{Case Reports in Neurology}

Case Rep Neurol 2021;13:31-34

\begin{tabular}{l|l}
\hline DOI: 10.1159/000511311 & ๑ 2021 The Author(s). Published by S. Karger AG, Basel \\
\hline
\end{tabular} www.karger.com/crn

Aiba et al.: Inner-Ear Symptom Heralds Basilar Stroke

man who most probably first experienced a labyrinthine artery occlusion, which heralded his basilar artery occlusion and cerebellar infarction.

\section{Case Report}

A 75-year-old Japanese man with hypertension, dyslipidemia, diabetes, and renal dysfunction that were being treated by a diabetologist suddenly experienced right deafness (right cochlear dysfunction) with vertigo and nystagmus to the left direction (right vestibular dysfunction). He was confirmed to have no otitis media or other organic etiologies by a local otologist. Three days after the onset of his inner-ear symptoms, he was referred and admitted to our hospital. A 3T MRI examination showed complete occlusion in the basilar artery (Fig. 1a, arrow) and no lesion in the right pons.

We initiated treatment with intravenous ozagrel (an antiplatelet agent) and edaravone, a free-radical scavenger. The next day, silent, small punctate high-signal foci at the right cerebellum of the right AICA/posterior inferior cerebellar artery (PICA) area appeared (Fig. 1b, arrows), but no pontine lesion was observed. Thin-slice MRI of the mastoid bone including the inner-ear organ did not visualize laterality. We did not perform gadolinium-enhancement MRI because of the patient's renal dysfunction. Soon after that examination, his right deafness and vertigo disappeared completely without the development of apparent cerebellar ataxia or coma.

\section{Discussion}

Regarding stroke, it is known that because the blood supply to the inner ear originates from the vertebrobasilar system, a vertebrobasilar ischemic stroke can present with vertigo and hearing loss due to infarction of the inner ear (i.e., a labyrinthine infarction). Sometimes, vertigo and hearing loss are warning symptoms of an impending vertebrobasilar ischemic stroke (mainly in the anterior inferior cerebellar artery territory) [2, 4]. It is known that among the vascular causes, ischemic stroke in the territory of the AICA is the leading cause of acute audiovestibular loss. The acute audiovestibular loss is usually associated with other neurological symptoms or signs, but can rarely occur in isolation (i.e., as a labyrinthine infarction) [5].

Although we could not directly visualize the inner-ear ischemia/occluded labyrinthine artery $[6,7]$ in our patient's case, we speculate that in light of his clinical course, his first symptoms (right cochlear and vestibular dysfunction) most probably reflected the right labyrinthine artery occlusion that heralded - or occurred together with - his basilar artery occlusion, which was followed by the right cerebellar infarction (which was clinically silent). Once a sudden inner ear dysfunction is encountered in a patient at risk of stroke (atherosclerosis risks, aging, etc.), clinicians should conduct further neurological examinations and neuroimaging and then start the appropriate therapy to prevent life-threatening brainstem complications.

In conclusion, a sudden inner ear dysfunction may herald a basilar stroke; clinicians should therefore initiate appropriate therapy to prevent life-threatening brainstem complications.

\section{Karger'=}




\section{Case Reports in Neurology}

\begin{tabular}{l|l}
\hline Case Rep Neurol 2021;13:31-34 \\
\hline DOI: 10.1159/000511311 & $\begin{array}{l}\text { @ 2021 The Author(s). Published by S. Karger AG, Basel } \\
\text { www.karger.com/crn }\end{array}$ \\
\hline
\end{tabular}

Aiba et al.: Inner-Ear Symptom Heralds Basilar Stroke

\section{Statement of Ethics}

We have obtained written informed consent from the patient for the publication of this case report and any accompanying images.

\section{Conflict of Interest Statement}

We have no conflicts of interest.

\section{Funding Sources}

We have no sponsors.

\section{Author Contributions}

Y. Aiba participated in the acquisition, analysis, and interpretation of data. R. Sakakibara participated in the study concept and design, acquisition of data, analysis and interpretation of data, and preparation of the manuscript. T. Yamaguchi participated in the acquisition of data. F. Tateno participated in the acquisition of data.

\section{References}

1 Weymouth W, Pedersen C. Central retinal artery occlusion associated with carotid artery occlusion. Clin Pract Cases Emerg Med. 2019 May;3(3):233-6.

2 von Campe G, Regli F, Bogousslavsky J. Heralding manifestations of basilar artery occlusion with lethal or severe stroke. J Neurol Neurosurg Psychiatry. 2003 Dec;74(12):1621-6.

3 Alonso F, Kassem MW, Iwanaga J, Oskouian RJ, Loukas M, Demerdash A, et al. Anterior inferior cerebellar arteries juxtaposed with the internal acoustic meatus and their relationship to the cranial nerve VII/VIII complex. Cureus. 2017 Aug;9(8):e1570.

4 Kim JS, Lee H. Inner ear dysfunction due to vertebrobasilar ischemic stroke. Semin Neurol. 2009 Nov;29(5):534-40.

5 Lee H, Ahn BH, Baloh RW. Sudden deafness with vertigo as a sole manifestation of anterior inferior cerebellar artery infarction. J Neurol Sci. 2004 Jul;222(1-2):105-7.

6 Lee SJ, Lee SA, Kim BG, Hong HS, Lee JY, Lee JD. Feasibility of magnetic resonance imaging in the differential diagnosis of isolated acute audiovestibular loss. J Vestib Res. 2018;28(5-6):385-91.

7 Eliezer M, Verillaud B, Guichard JP, Kania R, Toupet M, Herman P, et al. Labyrinthine infarction caused by vertebral artery dissection: consideration based on MRI. J Neurol. 2019 Oct;266(10):2575-7. 
Case Reports in Neurology
Case Rep Neurol 2021;13:31-34

\begin{tabular}{l|l} 
DOI: $10.1159 / 000511311$ & c 2021 The Author(s). Published by S. Karger AG, Basel
\end{tabular} www.karger.com/crn

Aiba et al.: Inner-Ear Symptom Heralds Basilar Stroke
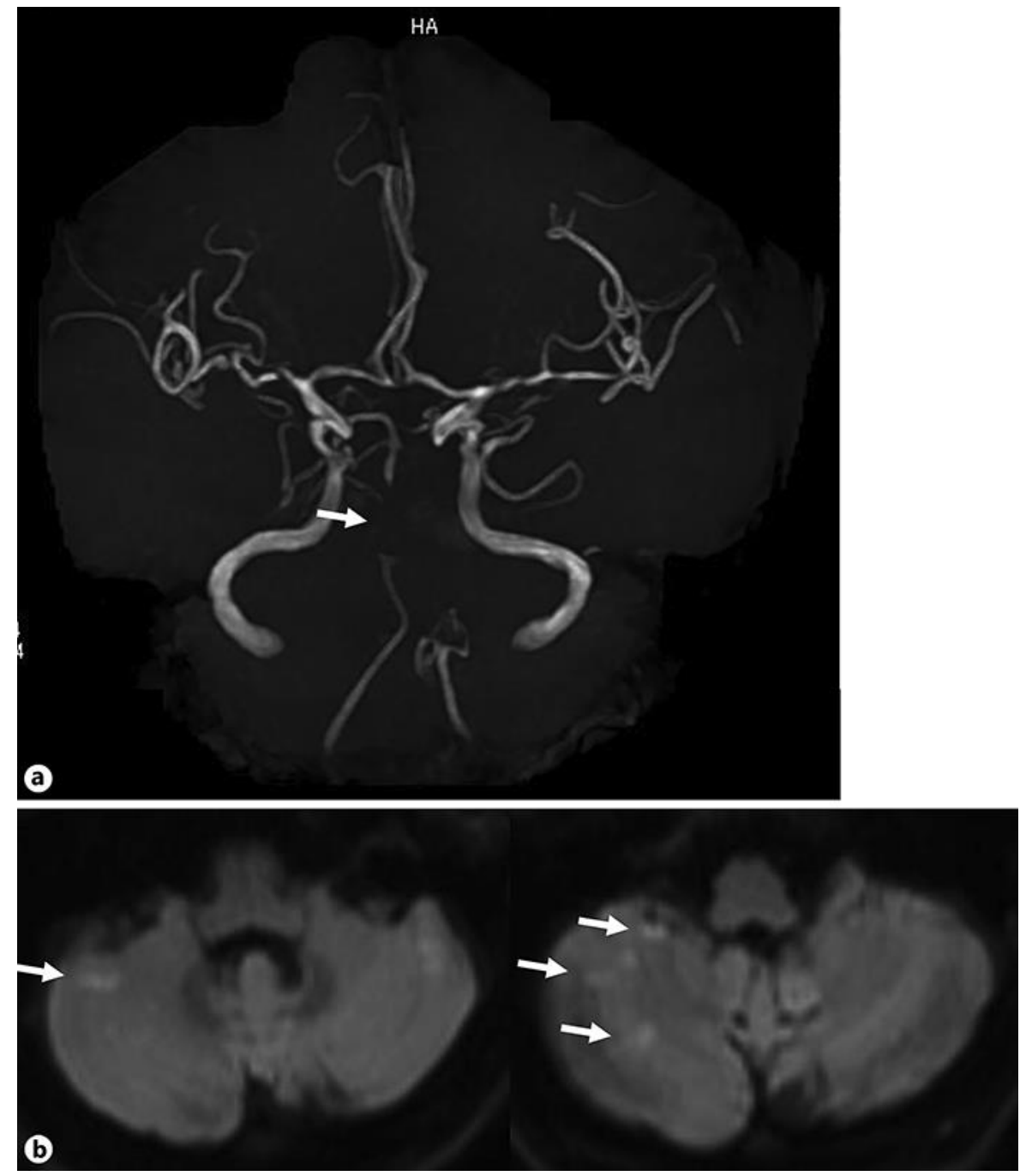

Fig. 1. MRI of the patient, a 75-year-old male. a On admission, 3T MRI revealed complete occlusion in the basilar artery (arrow). b On the day following the patient's admission, silent, small punctate high signal foci at the right cerebellum of the right AICA/PICA area appeared (arrows) but no pontine lesion was observed. 